\title{
Polymorphisms of interleukin-10 and its receptor and lung function in COPD
}

\author{
J-Q. He*, K. Shumansky*, X. Zhang*, J.E. Connett" ${ }^{*}$ N.R. Anthonisen \\ and A.J. Sandford*
}

ABSTRACT: Interleukin (IL)-10 is a type-2 T-helper cell cytokine with a broad spectrum of antiinflammatory actions. Inflammation plays an important role in the pathogenesis of chronic obstructive pulmonary disease. It was hypothesised that single nucleotide polymorphisms (SNPs) of the genes encoding IL-10 (IL10) and the $\alpha$ subunit of its receptor (IL10RA) are associated with changes in, or value of, forced expiratory volume in one second (FEV 1 ) in smoking-induced chronic obstructive pulmonary disease.

In total, eleven SNPs of IL10 and IL10RA were studied in 586 White subjects, selected from continuous smokers followed for 5 yrs in the Lung Health Study, who showed the fastest $(n=280)$ and slowest $(n=306)$ decline in FEV1. These 11 SNPs were also studied in 1,072 participants exhibiting the lowest $(n=538)$ and highest $(n=534)$ baseline $F E V_{1}$ at the beginning of the Lung Health Study.

No association was found in the primary analyses. Although a subgroup analysis showed that the IL-10 3368A allele was associated with a fast decline in $\mathrm{FEV}_{1}$, the association did not pass correction for multiple comparisons. No gene-gene interaction of IL10 with IL10RA was found.

There was no association of polymorphisms of the genes encoding interleukin-10 and the $\alpha$ subunit of its receptor with the rate of decline in, or value of, forced expiratory volume in one second in smoking-induced chronic obstructive pulmonary disease.

KEYWORDS: Chronic obstructive pulmonary disease, forced expiratory volume in one second, genetic polymorphism, interleukin-10, interleukin-10 receptor $\alpha$, lung function

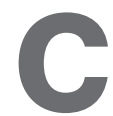
hronic obstructive pulmonary disease (COPD) is characterised by airway obstruction that is not fully reversible. Airway obstruction is defined as a ratio of forced expiratory volume in one second (FEV1) to forced vital capacity of $<0.70$. The FEV1, presented as a percentage of the predicted value for age, height, weight and race, defines disease severity. An accelerated rate of decline in FEV1 is the hallmark of COPD. Accumulating evidence suggests that genetic factors account for $30-50 \%$ of the variability in cross-sectional FEV1 [1, 2], and $18 \%$ of the variability in longitudinal change in FEV1 [3]. However, the genetic determinants of crosssectional and longitudinal lung function are not fully understood in smoking-induced COPD.

The interleukin (IL)-10 gene (IL10) is located at 1q31-32, a region not linked with lung function in COPD linkage studies [4-6]. IL10 was selected as a candidate gene based on its known function and previous association studies. IL-10 is a Thelper cell (Th) type 2 cytokine that has a broad spectrum of anti-inflammatory actions. IL-10 levels are reduced in induced sputum from patients with COPD, indicating that this might be a mechanism for increasing lung inflammation [7]. Several single nucleotide polymorphisms (SNPs) and haplotypes of IL10 have been associated with the level of expression of IL-10 $[8,9]$. The SNPs of IL10 were associated with FEV1 in asthmatic subjects [10]. A study showed that one IL10 SNP was associated with rate of decline in lung function in firefighters [11].

The IL-10 receptor (IL-10R) is a heterotetramer composed of two of each of the receptor chains IL-10R $\alpha$ and IL-10R $\beta$. The IL-10R $\alpha$ chain plays a dominant role in mediating high-affinity ligand binding and signal transduction, whereas the IL$10 \mathrm{R} \beta$ subunit is thought to be required for signalling alone. It was reported that two SNPs of the IL-10R $\alpha$ gene (IL10RA; located at 11q23.3), substitutions of serine 138 with glycine and of glycine 330 with arginine, have functional implications [12]. There is an interaction between the IL-10 and IL-10R complex; IL-10 stabilises dimerisation of both IL-10R subunits, and exerts a variety of immunoregulatory effects [13].

\section{AFFILIATIONS}

${ }^{*}$ The James Hogg iCAPTURE Centre for Cardiovascular and Pulmonary Research, St. Paul's Hospital, University of British Columbia, Vancouver, $\mathrm{BC}$, and

"Faculty of Medicine, University of Manitoba, Winnipeg, MB, Canada.

"Division of Biostatistics, School of Public Health, University of Minnesota, Minneapolis, MN, USA.

\section{CORRESPONDENCE}

A.J. Sandford UBC James Hogg iCAPTURE Centre for Cardiovascular and Pulmonary Research,

St. Paul's Hospital,

1081 Burrard Street,

Vancouver, BC,

V6Z 1Y6,

Canada.

Fax: 16048068351

E-mail: asandford@mrl.ubc.ca

Received:

January 082007

Accepted:

February 092007

\section{SUPPORT STATEMENT}

This study was supported by grants from the British Columbia Lung Association (Vancouver, BC, Canada), Canadian Institutes of Health Research (Ottawa, ON,

Canada) and National Institutes of Heath (Bethesda, MD, USA) Grant 5R01HL064068-04. The Lung Health Study was supported by contract N01-HR-46002 from the Division of Lung Diseases of the National Heart, Lung, and Blood Institute (Bethesda, MD, USA). A.J. Sandford is the recipient of a Canada Research (Ottawa, ON, Canada) Chair in genetics.

STATEMENT OF INTEREST None declared.

European Respiratory Journal Print ISSN 0903-1936

Online ISSN 1399-3003 
It was hypothesised that IL10 and IL10RA SNPS and their interaction influence the decline in, and/or cross-sectional value of, FEV1 in smoking-induced COPD. The Lung Health Study (LHS), sponsored by the National Heart, Lung and Blood Institute (Bethesda, MD, USA), was a clinical trial of the effects of smoking intervention and bronchodilator treatment on the progression of COPD [14]. This dataset provides an excellent opportunity for exploring genetic determinants of decline, in and/or cross-sectional level of, lung function in patients who exhibit smoking-induced COPD [15-18].

\section{METHODS}

\section{Study subjects}

The LHS recruited a total of 5,887 smokers, aged 35-60 yrs, showing spirometric evidence of mild-to-moderate lung function impairment from 10 North American medical centres [14]. From the LHS cohort, two nested case-control studies were designed to study genetic determinants of the rate of decline in FEV1 and cross-sectional FEV1. Based on the change in FEV1 during 5 yrs of follow-up, the 287 and 308 nonHispanic White subjects showing the highest (fast decline group) and slowest (nondecline group) rate of decline in FEV1 were selected from among 3,216 continuous smokers. From all remaining LHS participants, the 484 and 468 non-Hispanic White subjects showing the highest (high function group) and lowest (low function group) post-bronchodilator FEV1 (percent pred) at the start of the LHS were selected. Since 144 individuals from the rate of decline study groups exhibited baseline FEV1 within one of these categories (58 individuals in the high function group and 86 in the low function group), they were also analysed in the baseline function study. Thus there were 542 and 554 participants in the high and low function groups, respectively. Informed consent was obtained from all participants, and the present investigation received the approval of the Providence Health Care Research Ethics Board (Vancouver, BC, Canada).

\section{Tagging SNP selection}

The IL10 and IL10RA SNP discovery data were downloaded from the SeattleSNPs Website [19]. The IL-10 discovery data from the Innate Immunity Website [20] were incorporated into data from SeattleSNPs. From all SNPs identified in the 23 unrelated European-American samples from the Human Polymorphism Study Centre (CEPH) family panel, a set of tagging SNPs (tagSNPs) was chosen for each gene using the LDSelect program developed by CARLSON et al. [21]. A relatively stringent linkage disequilibrium (LD) threshold of $r^{2}>0.8$ and minor allele frequency of $10 \%$ was used. Four SNPs of IL10 (fig. 1) and seven of IL10RA were selected using the LDSelect program. The positions of the selected tagSNPs in the genes are shown in figures 2 and 3 . The corresponding reference sequence positions are shown in table 1.

\section{Genotyping}

Genotyping was performed in 384-well plates using the TaqMan 5' exonuclease assay with primers and probes supplied by the manufacturer (Applied Biosystems, Foster City, CA, USA). In each plate, 12 DNA samples from the CEPH panel of known genotype were included as positive controls, and eight wells lacking templates as negative controls. No

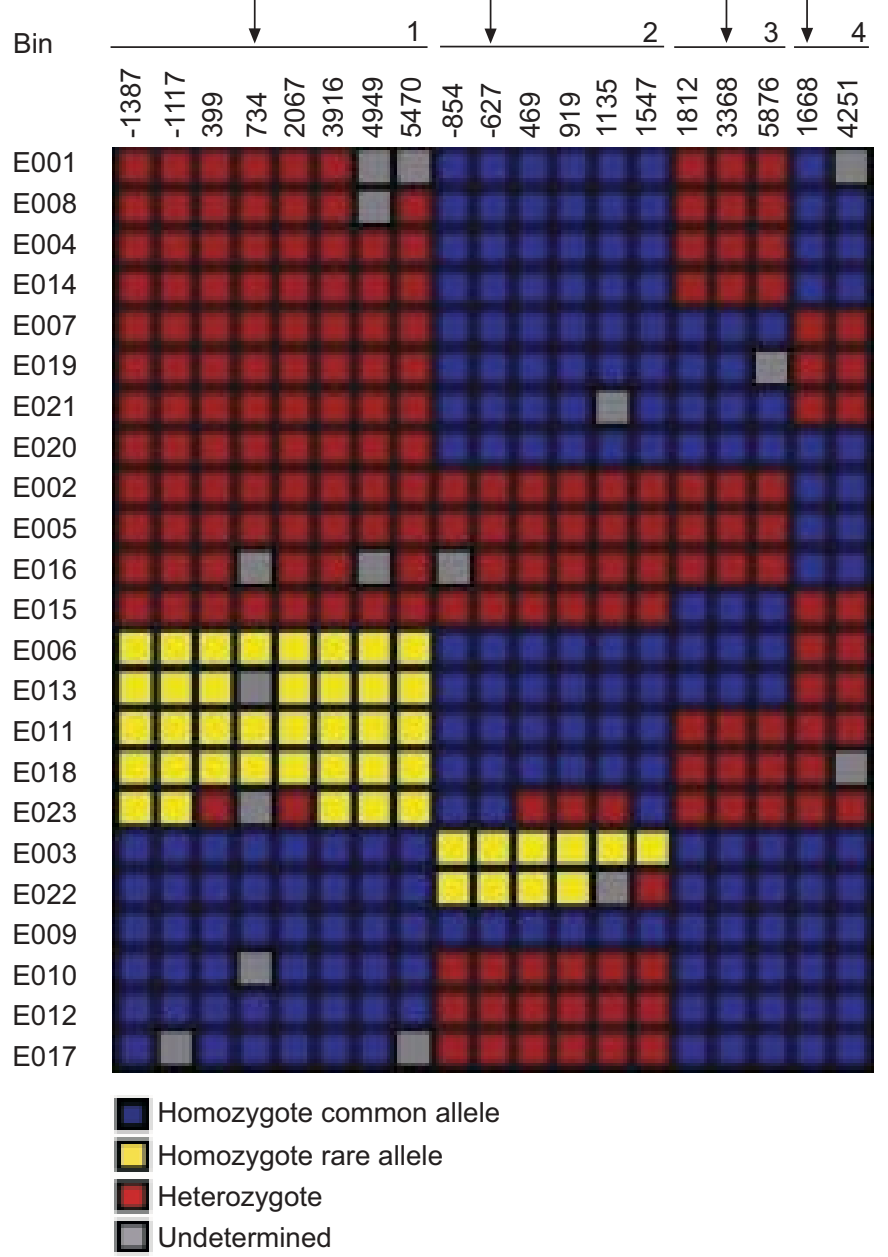

FIGURE 1. Tagging (tag) single nucleotide polymorphism (SNP) selection for the interleukin (IL)-10 gene SNPs using the LDSelect program [21]. The IL10 genotype data came from two sources, SeattleSNPs [19] and Innate Immunity [20] programmes for genomic applications. Each row corresponds to an individual DNA sample in the SeattleSNPs and Innate Immunity polymorphism discovery panel E001-E023 represent European-Americans. Columns correspond to polymorphic sites (numbers correspond to the site of the SNP within the gene). Sites are ordered by linkage disequilibrium, with sites showing similar genotype patterns placed in the same bin. All of the tagSNPs were selected; genotyped SNPs are indicated with vertical arrows.

errors were detected in the $10 \%$ of randomly selected samples that were genotyped in duplicate.

\section{Statistical analysis}

Hardy-Weinberg equilibrium tests and LD estimation were performed using $\mathrm{R}$ [22], as were all single-locus association tests. The codominant and additive models were tested first, and then, if there was a significant association, the dominant and recessive models were tested to see whether these models fitted better. If the cell counts were low, significance was assessed by permutation tests. The Armitage trend test [23] was used to test for an additive effect of the allele. In the rate of decline study, multivariate logistic regression analysis was used to adjust for confounding factors, such as age, sex, cumulative cigarette consumption and research centre. In the 


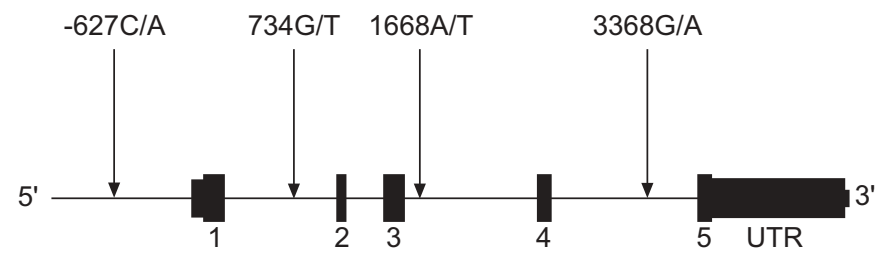

FIGURE 2. Position of single nucleotide polymorphisms within the interleukin-10 gene. Numbered regions represent exons. C: cytosine; A: adenine; G: guanine; T: thymidine; UTR: untranslated region.

baseline study, multivariate logistic regression was used to adjust for the aforementioned confounding factors and an additional rate of decline of lung function covariate.

Haplotype association was also tested using $R$ [24]. Expectation-maximisation was used to calculate haplotype frequencies.

\section{Gene-gene interactions}

The multifactor dimensionality reduction (MDR) and focused interaction testing framework (FITF) methods were used to explore gene-gene interactions. The MDR method is a nonparametric and genetic model-free alternative to logistic regression for detecting and characterising nonlinear interactions among factors associated with disease risk [25]. The more-recent FITF approach tests the association of marginal effects and interactions using a logistic regression framework in a series of stages, the number of interacting loci considered increasing with each subsequent stage [26].

\section{RESULTS}

\section{Characteristics of the study groups}

The characteristics of the study participants are shown in table 2. Since no DNA was available for nine subjects in the decline study and 24 in the baseline FEV1 study, the numbers of participants in the two studies were 586 and 1,072, respectively. There were significant differences in several potential confounding factors, such as age, sex and cigarette smoking history (in pack-years) between the fast and nondecline FEV1 groups and also the high and low function (FEV1) groups. Therefore, the associations of alleles, genotypes and haplotypes with lung function were analysed using logistic regression to adjust for these factors.

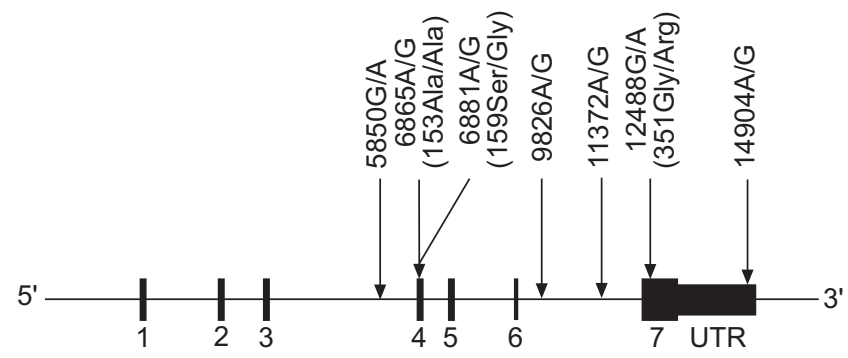

FIGURE 3. Position of single nucleotide polymorphisms within the interleukin-10 receptor $\alpha$ gene. Numbered regions represent exons. G: guanine; A: adenine; Ala: alanine; Ser: serine; Gly: glycine; Arg: arginine; UTR: untranslated region.
The allele frequencies of all 11 SNPs did not significantly deviate from Hardy-Weinberg equilibrium in the nondecline and high function groups.

\section{Single SNP analysis}

The minor allele frequencies of the IL10 and IL10RA SNPs in different study groups are shown in table 3. Multivariate logistic regression analysis was used to adjust for confounding factors, such as age, sex, cumulative cigarette consumption and research centre, in the rate of decline study, and the aforementioned confounding factors and an additional rate of decline of lung function covariate in the baseline study. There was no association of any of the 11 SNPs studied with rate of decline or level of FEV1 in additive and codominant genetic models before or after adjustment for confounding factors ( $\mathrm{p}>0.05$ for all).

In a subgroup analysis stratified by sex, a significant association of the IL10 3368G/A SNP with rate of decline in FEV1 was found in female participants; the frequencies of the 3368A allele were 14.9 and $22.6 \%$ in nondecliners and fast decliners, respectively $(\mathrm{p}=0.02$ for the additive model; odds ratio 1.92 (95\% confidence interval 1.06-3.48). However, this association did not survive correction for multiple comparisons.

\section{Haplotype analysis}

Logistic regression analysis was performed to estimate haplotype disease association. The haplotype frequencies inferred by the expectation-maximisation algorithm are presented in table 4 . In the rate of decline study, the four IL10 and seven IL10RA SNP haplotypes were not associated with lung function decline ( $p>0.05$ for all). In the baseline lung function study, the frequency of the IL10RA haplotype 5850A/6865A/ 6881G/9826A/1371G/12488A/14904G (AAGAGAG) was significantly lower in the high versus the low function group (14.1 versus $15.0 \%$ ) compared with the GGAGGGA haplotype as a reference (adjusted $\mathrm{p}=0.02$ ). The frequency of the ILI0RA haplotype GGAGGGG was marginally lower in the high versus the low function group (7.2 versus $8.9 \%$ ) compared with the GGAGGGA haplotype as a reference (adjusted $\mathrm{p}=0.05$ ). However, there were no significant differences in global haplotype tests of association.

\section{Gene-gene interaction}

The IL10 and IL10RA interaction of all possible two-to-fourlocus models was explored using the MDR method. There was no evidence of epistasis (gene-gene interaction; detailed results not shown). The result of no epistasis was further confirmed using the FITF strategy, which was suggested to be more powerful than MDR (detailed results not shown) [26].

\section{DISCUSSION}

Association studies of the IL10 and IL10RA SNPs with rate of decline and baseline FEV1 were performed using two nested case-control studies in the LHS. No association was found with either the rate of decline in, or level of, lung function in smoking-induced COPD subjects.

Several lines of evidence drove the analysis of the present data to be stratified by sex. First, it was reported that females might be more susceptible to the development of severe COPD [27]. Secondly, there was a lower Th1/Th2 cytokine production 
TABLE 1 Nomenclature of single nucleotide polymorphisms (SNPS) utilised in present study

\begin{tabular}{|c|c|c|c|c|c|c|}
\hline Gene & SNP ID & Nucleotides & Position in RefSeq & Position in gene & Position in protein & Names in literature \\
\hline \multirow[t]{3}{*}{ IL10 } & rs1800872 & $\mathrm{C} / \mathrm{A}$ & 472 & -627 (promoter) & & -592 \\
\hline & rs3024492 & $\mathrm{A} / \mathrm{T}$ & 2767 & 1668 (intron 3) & & \\
\hline & rs3024495 & $G / A$ & 4467 & 3368 (intron 4) & & \\
\hline \multirow[t]{5}{*}{ IL10RA } & rs10750121 & $G / A$ & 8506 & 5850 (intron 3) & & \\
\hline & rs2512146 & $A / G$ & 12482 & 9826 (intron 6) & & \\
\hline & rs4252286 & $A / G$ & 14028 & 11372 (intron 6) & & \\
\hline & rs2229113 & $G / A$ & 15144 & 12488 (exon 7) & ${ }^{351}$ Gly/Arg & ${ }^{330}$ Gly/Arg \\
\hline & rs9610 & $\mathrm{A} / \mathrm{G}$ & 17560 & 14904 (3' UTR) & & \\
\hline
\end{tabular}

The reference sequences (RefSeqs) of the genes encoding interleukin (IL)-10 and the $\alpha$ subunit of its receptor (IL10RA) are AF418271 and AY195619, respectively. Gene positions are numbered by denoting the first nucleotide of the initiator methionine codon as +1 (position 1099 in AF418271 and position 2657 in AY195619). The presence of an insertion/deletion polymorphism in $/ L 10$ leads to a discrepancy between the numbering derived from AF418271 and that commonly used in the literature. In order to make the numbering comparable with published SNP positions, the numbers of three of the IL10 SNPs were adjusted. Thus rs3024491, rs3024492 and rs3024495 occur at positions 735, 1669 and 3369 of AF418271, respectively. The numbers used here and elsewhere in the present article are those found in the previous literature. ID: identifier; C: cytosine; A: adenine; G: guanine; T: thymidine; Ala: alanine; Ser: serine; Gly: glycine; Arg: arginine; UTR: untranslated region.

ratio by stimulated T-cells in females compared with males, which was due to females exhibiting lower levels of Th1 cytokines (IL-2 and interferon- $\gamma$ ) and higher levels of Th2 cytokines (IL-10 and -4) after stimulation [28]. Thirdly, several studies have demonstrated that associations of IL10 SNPs with IL-10 expression levels and diseases are sex-specific [29-31]. Although a subgroup analysis stratified by sex showed that the IL10 3368A allele was associated with a fast decline in FEV1 ( $p=0.02$ for the additive model), the association disappeared after adjustment for multiple comparisons.

There have been three previous studies of IL10 SNPs and lung function or COPD (table 5) [10, 11, 32]. In order to compare the present results with those of previous studies, LD information must be established for all studied SNPs. The SeattleSNPs and
Innate Immunity SNP discovery data in European-Americans (fig. 1) are shown in table 5. IL10 734G/T was in perfect LD with IL10 -1117A/G (IL10 1082 in [10]) and IL10 3916T/C (IL10 4299 in [10]). Similarly, IL10 -627C/A was in almost perfect LD with IL10 -854C/T $\left(\mathrm{R}^{2}=0.94\right)$ [10], and IL10 3368G/A was in perfect LD with IL10 1812G/T (fig. 1).

A comparison of the present data and previously reported results is presented in table 5. Although all three previous studies concluded that IL10 SNPs were associated with FEV1 or FEV1 change, either the study subjects were not COPD patients or the associations would disappear if adjusted for multiple comparisons. In the report of BURGESS et al. [11], the rate of FEV1 decline was studied in 379 firefighters with respect to five IL10 SNPs, and only a single SNP (1668AA homozygote)

TABLE 2 Distribution of demographic characteristics in fast/nondecline and high/low function groups

\begin{tabular}{|c|c|c|c|c|c|c|}
\hline & \multicolumn{3}{|c|}{ Decline in FEV1 study } & \multicolumn{3}{|c|}{ Baseline FEV1 study } \\
\hline & Fast decline & Nondecline & p-value & High function & Low function & p-value \\
\hline Subjects $n$ & 280 & 306 & & 534 & 538 & \\
\hline Males/females n & $163 / 117$ & $204 / 102$ & 0.0346 & $354 / 180$ & $333 / 205$ & 0.1336 \\
\hline Age yrs & $49.5 \pm 0.38$ & $47.6 \pm 0.39$ & 0.0005 & $46.2 \pm 0.3$ & $50.7 \pm 0.3$ & $<0.0001$ \\
\hline Pre-BD & $-4.14 \pm 0.06$ & $1.08 \pm 0.04$ & $<0.0001$ & $-0.55 \pm 0.07$ & $-1.27 \pm 0.08$ & $<0.0001$ \\
\hline Post-BD & $-3.43 \pm 0.08$ & $0.67 \pm 0.05$ & $<0.0001$ & $-0.75 \pm 0.06$ & $-0.79 \pm 0.08$ & 0.7227 \\
\hline \multicolumn{7}{|l|}{ Baseline FEV ${ }_{1}{ }^{\circ} \%$ pred } \\
\hline Pre-BD & $72.6 \pm 0.53$ & $75.6 \pm 0.46$ & $<0.0001$ & $86.5 \pm 0.1$ & $61.1 \pm 0.2$ & $<0.0001$ \\
\hline Post-BD & $91.8 \pm 0.1$ & $62.6 \pm 0.1$ & $<0.0001$ & $91.8 \pm 0.1$ & $62.6 \pm 0.1$ & $<0.0001$ \\
\hline
\end{tabular}

Data are presented as mean \pm SEM, unless otherwise stated. FEV1: forced expiratory volume in one second; $\Delta$ : change; \% pred: \% predicted; Pre-BD: pre-bronchodilator; Post-BD: post-bronchodilator. ${ }^{*}$ : determined over 5 -yr period; " : at start of Lung Health Study. 


\begin{tabular}{|c|c|c|c|c|c|}
\hline \multicolumn{2}{|c|}{ TABLE 3} & \multicolumn{4}{|c|}{$\begin{array}{l}\text { Minor allele frequencies of single nucleotide } \\
\text { polymorphisms (SNPs) in the study groups }\end{array}$} \\
\hline \multirow[t]{2}{*}{ Gene } & \multirow[t]{2}{*}{ SNP } & \multicolumn{2}{|c|}{ Rate of decline study } & \multicolumn{2}{|c|}{ Baseline study } \\
\hline & & $\begin{array}{l}\text { Non- } \\
\text { decline }\end{array}$ & $\begin{array}{c}\text { Fast } \\
\text { decline }\end{array}$ & $\begin{array}{l}\text { High } \\
\text { function }\end{array}$ & $\begin{array}{l}\text { Low } \\
\text { function }\end{array}$ \\
\hline \multirow[t]{4}{*}{ IL10 } & $-627 \mathrm{C} / \mathrm{A}$ & 23.1 & 20.9 & 22.1 & 20.6 \\
\hline & $734 \mathrm{G} / \mathrm{T}$ & 48.7 & 52.9 & 49.8 & 51.7 \\
\hline & $1668 \mathrm{~A} / \mathrm{T}$ & 28.3 & 27.0 & 28.1 & 26.0 \\
\hline & $3368 \mathrm{G} / \mathrm{A}$ & 14.9 & 19.1 & 14.6 & 15.8 \\
\hline \multirow{7}{*}{ IL10RA } & $5850 \mathrm{G} / \mathrm{A}$ & 30.8 & 30.9 & 31.8 & 30.5 \\
\hline & $6865 A / G$ & 45.8 & 45.4 & 47.1 & 46.6 \\
\hline & $6881 A / G$ & 16.1 & 15.9 & 15.8 & 16.1 \\
\hline & $9826 A / G$ & 30.6 & 30.3 & 31.7 & 30.1 \\
\hline & $11372 A / G$ & 3.8 & 2.9 & 2.6 & 2.8 \\
\hline & $12488 \mathrm{G} / \mathrm{A}$ & 30.1 & 29.6 & 30.1 & 29.3 \\
\hline & $14904 \mathrm{~A} / \mathrm{G}$ & 46.7 & 47.3 & 46.7 & 45.5 \\
\hline
\end{tabular}

IL10: interleukin (IL)-10 gene; IL10RA: IL-10 receptor $\alpha$ gene; C: cytosine; A: adenine; G: guanine; T: thymidine. $p>0.05$ for all in both studies in additive and codominant models.

was found to be associated with FEV1 decline ( $p=0.023$ before adjusting for multiple comparisons). In the paper of SEIFART et al. [32], five SNPs were studied in three groups (COPD patients, population controls and matched controls), and only moderate evidence of association with COPD was found for

\begin{tabular}{|c|c|c|c|c|c|}
\hline \multirow[t]{3}{*}{ TABL } & \multicolumn{5}{|c|}{$\begin{array}{l}\text { Haplotype frequencies inferred using the } \\
\text { expectation-maximisation algorithm in non-/fast } \\
\text { decline and high/low function participants }\end{array}$} \\
\hline & \multirow[t]{2}{*}{ Haplotype } & \multicolumn{2}{|c|}{ Rate of decline study } & \multicolumn{2}{|c|}{ Baseline study } \\
\hline & & $\begin{array}{l}\text { Non- } \\
\text { decline }\end{array}$ & $\begin{array}{c}\text { Fast } \\
\text { decline }\end{array}$ & $\begin{array}{c}\text { High } \\
\text { function }\end{array}$ & $\begin{array}{l}\text { Low } \\
\text { function }\end{array}$ \\
\hline \multirow[t]{6}{*}{ IL10 } & AGAG & 23.0 & 20.9 & 22.1 & 20.6 \\
\hline & CGAG & 28.1 & 26.3 & 27.7 & 31.0 \\
\hline & CTTG & 28.0 & 26.9 & 28.2 & 26.0 \\
\hline & CTAG & 5.8 & 7.0 & 7.4 & 6.7 \\
\hline & CTAA & 14.9 & 19.1 & 14.5 & 15.7 \\
\hline & Others & 0.2 & 0.0 & 0.1 & 0.0 \\
\hline \multirow[t]{7}{*}{ IL10RA } & GGAGGGA & 42.5 & 43.3 & 43.1 & 41.6 \\
\hline & GGAGGGG & 7.8 & 8.1 & 7.2 & 8.9 \\
\hline & GGAGAGA & 3.8 & 2.9 & 2.4 & 2.8 \\
\hline & GAAGGGG & 14.8 & 14.4 & 15.2 & 15.8 \\
\hline & AAAAGAG & 14.5 & 14.5 & 15.7 & 13.9 \\
\hline & AAGAGAG & 15.3 & 14.5 & 14.1 & 15.0 \\
\hline & Others & 1.3 & 2.3 & 2.3 & 2.0 \\
\hline
\end{tabular}

The single nucleotide polymorphisms (SNPs) comprising the interleukin (IL)-10 gene (IL10) haplotypes are -627C/A, 734G/T, 1668A/T and 3368G/A. The SNPs comprising the IL-10 receptor $\alpha$ gene (IL10RA) haplotypes are: 5850G/A, 6865A/G, 6881A/G, 9826A/G, 11371A/G, 12488G/A and 14904A/G. A: adenine; G: guanine; C: cytosine; $\mathrm{T}$ : thymidine.
IL10-1082A/G compared with population controls before adjusting for multiple comparisons $(p=0.0247$ for genotype distribution; $p=0.047$ for allele frequency). In addition, the associations of these two studies were not found for the same SNP or SNPs in the same LD bin. Therefore, the positive associations in these two studies may represent a type I error.

In the study of LYON et al. [10], which included 518 Caucasian asthmatic children from the Childhood Asthma Management Program (CAMP) and their parents, IL10 4299T/C was significantly associated with FEV1 (percent pred) in both the family and population analyses $(p=0.0002)$, which were still significant even after adjusting for multiple comparisons.

There are several explanations for the inconsistency of the present results compared with those of LYON et al. [10]. The first and most important concern is the issue of the power of the study when a negative result is found. IL10 4299T/C was in perfect LD with IL10 734G/T, as mentioned above, and the IL10 4299T allele frequency was $48.5 \%$ in the CAMP study, which is similar to the IL10 734T allele frequency in the present study $(48.7-52.9 \%$ in four different phenotypic groups). The results of previous power analysis in the present study samples showed that, for an allele frequency of $48.7 \%$ and the genetic models studied, there was a $>90 \%$ power for detecting an allele/genotype relative risk in the region of $\geqslant 1.5$ in the baseline lung function groups [33]. Therefore, it is unlikely that the present negative association was due to lack of power. Secondly, the subjects in the CAMP study were asthmatic children, whereas the present study subjects were adults with smoking-induced COPD. The factors that determine baseline lung function may be different in these two different disease entities and/or age groups.

The effects of interaction of IL10 and IL1ORA SNPS on the rate of decline and baseline FEV1 were explored using both MDR and FITF methods, but there was no evidence of gene-gene interaction. Since relatively stringent criteria were used to select tagSNPs and powerful methodologies were used to perform the analysis, this observation is probably correct.

\section{SUMMARY}

There was no association of single nucleotide polymorphisms of the genes encoding interleukin-10 and the $\alpha$ subunit of its receptor with rate of decline in, or level of, forced expiratory volume in one second in patients with mild-to-moderate smoking-induced chronic obstructive pulmonary disease.

\section{ACKNOWLEDGEMENTS}

The authors gratefully acknowledge the National Heart, Lung, and Blood Institute for the recruitment and characterisation of the present study.

\section{REFERENCES}

1 Lewitter FI, Tager IB, McGue M, Tishler PV, Speizer FE. Genetic and environmental determinants of level of pulmonary function. Am J Epidemiol 1984; 120: 518-530.

2 Wilk JB, Djousse L, Arnett DK, et al. Evidence for major genes influencing pulmonary function in the NHLBI family heart study. Genet Epidemiol 2000; 19: 81-94. 


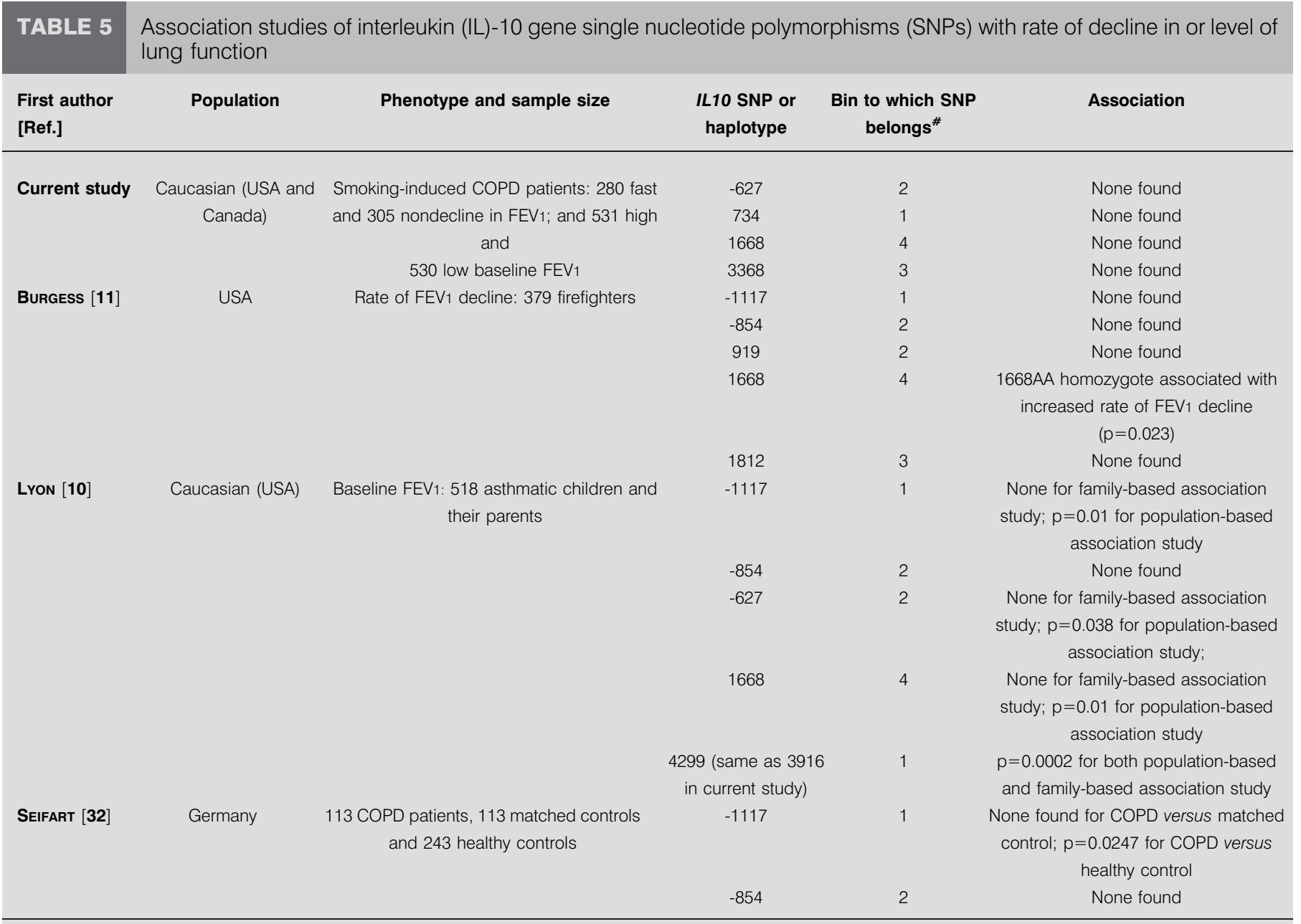

COPD: chronic obstructive pulmonary disease; FEV1: forced expiratory volume in one second. ${ }^{\#}$ : derived from the LDSelect, program [21]; SNPs in the same bin show high linkage disequilibrium and, therefore, provide similar genetic information.

3 Gottlieb DJ, Wilk JB, Harmon M, et al. Heritability of longitudinal change in lung function. The Framingham study. Am J Respir Crit Care Med 2001; 164: 1655-1659.

4 Joost O, Wilk JB, Cupples LA, et al. Genetic loci influencing lung function: a genome-wide scan in the Framingham Study. Am J Respir Crit Care Med 2002; 165: 795-799.

5 Wilk JB, DeStefano AL, Arnett DK, et al. A genome-wide scan of pulmonary function measures in the National Heart, Lung, and Blood Institute Family Heart Study. Am J Respir Crit Care Med 2003; 167: 1528-1533.

6 Silverman EK, Palmer LJ, Mosley JD, et al. Genomewide linkage analysis of quantitative spirometric phenotypes in severe early-onset chronic obstructive pulmonary disease. Am J Hum Genet 2002; 70: 1229-1239.

7 Takanashi S, Hasegawa Y, Kanehira Y, et al. Interleukin-10 level in sputum is reduced in bronchial asthma, COPD and in smokers. Eur Respir J 1999; 14: 309-314.

8 Kurreeman FA, Schonkeren JJ, Heijmans BT, Toes RE, Huizinga TW. Transcription of the IL10 gene reveals allelespecific regulation at the mRNA level. Hum Mol Genet 2004; 13: 1755-1762.
9 Turner DM, Williams DM, Sankaran D, Lazarus M, Sinnott PJ, Hutchinson IV. An investigation of polymorphism in the interleukin-10 gene promoter. Eur J Immunogenet 1997; 24: 1-8.

10 Lyon H, Lange C, Lake S, et al. IL10 gene polymorphisms are associated with asthma phenotypes in children. Genet Epidemiol 2004; 26: 155-165.

11 Burgess JL, Fierro MA, Lantz RC, et al. Longitudinal decline in lung function: evaluation of interleukin-10 genetic polymorphisms in firefighters. J Occup Environ Med 2004; 46: 1013-1022.

12 Gasche C, Grundtner P, Zwirn P, et al. Novel variants of the IL-10 receptor 1 affect inhibition of monocyte TNF- $\alpha$ production. J Immunol 2003; 170: 5578-5582.

13 Moore KW, de Waal Malefyt R, Coffman RL, O'Garra A. Interleukin-10 and the interleukin-10 receptor. Annu Rev Immunol 2001; 19: 683-765.

14 Anthonisen NR, Connett JE, Kiley JP, et al. Effects of smoking intervention and the use of an inhaled anticholinergic bronchodilator on the rate of decline of FEV1. The Lung Health Study. JAMA 1994; 272: 1497-1505. 
15 Sandford AJ, Chagani T, Weir TD, Connett JE, Anthonisen NR, Paré PD. Susceptibility genes for rapid decline of lung function in the Lung Health Study. Am J Respir Crit Care Med 2001; 163: 469-473.

16 He JQ, Connett J, Anthonisen N, Paré P, Sandford A. The effects of polymorphisms of GSTM1, T1 and P1 gene or their interaction with cigarette exposure on lung function. Am J Respir Crit Care Med 2003; 167: A744.

17 He JQ, Connett JE, Anthonisen NR, Pare PD, Sandford AJ. Glutathione $S$-transferase variants and their interaction with smoking on lung function. Am J Respir Crit Care Med 2004; 170: 388-394.

$18 \mathrm{He}$ JQ, Connett JE, Anthonisen NR, Sandford AJ. Polymorphisms in the IL13, IL13RA1, and IL4RA genes and rate of decline in lung function in smokers. Am J Respir Cell Mol Biol 2003; 28: 379-385.

19 National Heart, Lung and Blood Institute. SeattleSNPs Variation Discovery Resource. http://pga.gs.washington. edu Date last accessed: October 2003.

20 Channing Laboratory. Innate Immunity in Heart, Lung and Blood Disease. Programs for Genomic Applications. http://innateimmunity.net/ Date last accessed October 2003.

21 Carlson CS, Eberle MA, Rieder MJ, Yi Q, Kruglyak L, Nickerson DA. Selecting a maximally informative set of single-nucleotide polymorphisms for association analyses using linkage disequilibrium. Am J Hum Genet 2004; 74: 106-120.

22 Hornik K, ed. Frequently Asked Questions on R. R: a Language and Environment for Statistical Computing. Vienna, 2004. http:/ /www.r-project.org/

23 Armitage P. Tests for linear trends in proportions and frequencies. Biometrics 1955; 11: 375-386.
24 Burkett K, McNeney B, Graham J. A note on inference of trait associations with SNP haplotypes and other attributes in generalized linear models. Hum Hered 2004; 57: 200-206.

25 Hahn LW, Ritchie MD, Moore JH. Multifactor dimensionality reduction software for detecting gene-gene and geneenvironment interactions. Bioinformatics 2003; 19: 376-382.

26 Millstein J, Conti DV, Gilliland FD, Gauderman WJ. A testing framework for identifying susceptibility genes in the presence of epistasis. Am J Hum Genet 2006; 78: 15-27.

27 Silverman EK, Weiss ST, Drazen JM, et al. Gender-related differences in severe, early-onset chronic obstructive pulmonary disease. Am J Respir Crit Care Med 2000; 162: 2152-2158.

28 Giron-Gonzalez JA, Moral FJ, Elvira J, et al. Consistent production of a higher TH1:TH2 cytokine ratio by stimulated T cells in men compared with women. Eur J Endocrinol 2000; 143: 31-36.

29 Reuss E, Fimmers R, Kruger A, Becker C, Rittner C, Hohler T. Differential regulation of interleukin-10 production by genetic and environmental factors - a twin study. Genes Immun 2002; 3: 407-413.

30 Lio D, Scola L, Crivello A, et al. Gender-specific association between -1082 IL-10 promoter polymorphism and longevity. Genes Immun 2002; 3: 30-33.

31 Padyukov L, Hytonen AM, Smolnikova M, et al. Polymorphism in promoter region of IL10 gene is associated with rheumatoid arthritis in women. J Rheumatol 2004; 31: 422-425.

32 Seifart C, Dempfle A, Plagens A, et al. TNF- $\alpha-$, TNF- $\beta-$, IL-6-, and IL-10-promoter polymorphisms in patients with chronic obstructive pulmonary disease. Tissue Antigens 2005; 65: 93-100.

33 Tanaka G, Sandford AJ, Burkett K, et al. Tumour necrosis factor and lymphotoxin A polymorphisms and lung function in smokers. Eur Respir J 2007; 29: 34-41. 